\title{
Determinants of underweight among 6-59 months old children in Berahle, Afar, North East Ethiopia: a case control study 2016
}

\author{
Solomon Hintsa ${ }^{1 *}$ (D) and Kiros Gereziher ${ }^{2}$
}

\begin{abstract}
Objective: The objective of this study was to identify determinants of underweight among 6-59 months old children in Berahle Woreda, Afar, North East Ethiopia, in 2016.

Result: The median age (IQR) of cases and controls were 24 (34) and 18 (23) months respectively and $51.6 \%$ of the children were not exclusively breast-fed but $64.8 \%$ controls were exclusively breastfed. Age group of $48-59$ months $(A O R=11.93 ; 95 \% \mathrm{Cl} 3.88-36.67)$, illiterate mothers $(A O R=2.32 ; 95 \% \mathrm{Cl} 1.19-4.55)$, low dietary diversity $(A O R=4.57$; $95 \% \mathrm{Cl} 2.40-8.69)$, diarrhea in the past of 2 weeks $(A O R=2.93 ; 95 \% \mathrm{Cl} 1.46-5.85)$, birth interval $(A O R=5.17 ; 95 \%$ $\mathrm{Cl} 2.37-11.26)$ and unprotected source of water $(A O R=2.62 ; 95 \% \mathrm{Cl} 1.42-4.85)$ were determinant factors of underweight.
\end{abstract}

Keywords: Determinants, Underweight, 6-59 months, Berahle, Afar, Ethiopia

\section{Introduction}

Malnutrition is defined as a pathological state resulting from complete, relative deficiency or excess of one or more of the crucial nutrients [1]. It is both medical and social disorder [2].

True underweight may be a sign of dietary, health, or emotional problems [3]. According to the WHO growth standard, underweight in under-five is measured by weight for age and it is the best global indicator of wellbeing in children $[4,5]$.

Underweight continues as a major public health problem in developing countries. It is the risk factor of the greatest loss of disability-adjusted life years (DALYs [6]). Even though child underweight is a global problem but the magnitude varies [7]. Underweight is highly associated with poverty [8]. In Ethiopia underweight in children

\footnotetext{
*Correspondence: solomonhintsa2013@gmail.com

${ }^{1}$ Department of Epidemiology and Biostatistics, School of Public Health,

College of Health Science, Aksum University, P. O. Box: 298, Aksum, Ethiopia

Full list of author information is available at the end of the article
}

is one of the public health problems [9]. In Sub-Saharan Africa (SSA) underweight is contributing to morbidity and mortality in under 5 years [10].

The period vulnerability to nutritional deficiencies is in the early life of pregnancy to 2 years old. Chronic undernutrition in early childhood also results in diminished cognitive and physical development $[11,12]$.

Half of all deaths in under-five children were attributed to undernutrition. This translates into the unnecessary loss of about 3 million young lives a year [13]. According to the 2013 united nation children's fund, WHO and the World Bank joint database, globally an estimated 101 million children under 5 years of age or $16 \%$ were underweight in 2011 [14]. West and Central Africa have experienced the smallest relative decrease, with an underweight prevalence of $22 \%$ in 2014, down from 31\% in 1990 [15].

Although the worldwide prevalence of underweight among under-five children has decreased since 1990, still millions of children remain at risk [16]. According to Mini Ethiopian Demographic and Health Survey (MEDHS) 2014 data, overall in Ethiopia 25\% of underfive is underweight: prevalence differs across the regions 
where; in Addis Ababa is 7.2\% and in Afar is $45.6 \%$ [17, 18].

Common risk factors of undernutrition are low socioeconomic status, low paternal education, lack of sanitation, diarrhea, infections, family size, low birth weight, children age and short birth interval, social and cultural causes, inadequate exclusive breastfeeding, unsuitable complementary feeding, insufficient energy and micronutrient intake, birth order, food availability, housing condition, health services and vaccination status [19-24].

Despite the great focus on child nutrition by the Ethiopian government and partners, underweight is still a public health problem suggesting some factors need to be identified [17]. Therefore, the goal of this study was to identify the determinant factors of underweight among 6-59 months old children.

\section{Main text}

\section{Study design and area}

A case-control study was conducted in Berahle woreda from January 1-March 1/2016. Berahle woreda is found in Afar regional state which is $883 \mathrm{~km}$ north of Addis Ababa. The total population of the district is expected to 94,082 based on the census of 2007 where 3575 are under-five children. The district has 04 health centers and 09 health posts. The population are pastoralist community and their life depends on animal production.

\section{Study population}

The source population was all 06-59 months old children living in Berahle woreda. Underweight children were those below -2 standard deviations and Normal-weight children were those between -2 and +2 standard deviations from the median weight-for-age of the $\mathrm{WHO} /$ NCHS reference population.

Sample size was determined; by EpiInfo statistical software to determine two-population proportion [25] using $95 \% \mathrm{CI}$, Power $80 \%$, control to case ratio 2 , OR $=2.3,38 \%$ of exposure among case, $21 \%$ of exposure among controls, $10 \%$ non-response rate and 1.5 design effect: total calculated sample size was 375 (125 cases and 250 controls). A multi-stage random sampling procedure was used to select study participants. Four Kebeles (smaller administrative units) were selected by simple random sampling from nine Kebeles. A preliminary survey was conducted to differentiate cases and controls in the four Kebeles. We use WHO/NCHS median weight-for-age to identify normal (between -2 and +2 SD) and underweight $(<-2 \mathrm{SD})$ children. According to the survey, 419 cases and 1164 controls identified. Cases and controls were proportionally allocated for each kebele.

\section{Data collection tools process}

Questioner was developed from a standard questionnaire of WHO, EDHS and relevant literature review [17, 25]. The questionnaire was prepared in English and translated to the local language (Afar afe) then retranslated back to English. The questionnaire was pretested in $10 \%$ of the total sample size Abala district. Data were collected from mothers or caregivers who had 6-59 months old child by interview and measurement. Four trained health extension workers (community health professionals) were recruited as data collectors and supervised by 2 nurses. Daily supervision was conducted to follow for completeness and consistency of the data.

The content of the questionnaire was socio-demographic, maternal and childcare characteristics, environmental health and dietary history based on 24-h recall.

Anthropometric measurements were measured using the standard technique. Weight of the child and mothers or caregivers were measured with light clothing and without shoes using UNICEF Electronic Scale with an accuracy of $0.1 \mathrm{~kg}$. The mother was weighed with the child and weigh without the child and then subtract the weight of the mother from the total weight to get the weight of the child [25]. Height was measured using Stadiometer (Seca, Germany) in centimeter $(\mathrm{cm})$ in an erect position that the back of the head, shoulder blades, buttocks, and heels make contact with the backboard at a precision of $0.1 \mathrm{~cm}$.

\section{Data analysis and management}

Collected data were cleaned, edited, coded and entered into Epi data software version 3.1 and exported to SPSS version 20. Descriptive statistics were presented in tables. Variables with $\mathrm{P}$-value $<.25$ in Bivariable logistic regression were taken to multiple Logistic regression. A backward likelihood ratio with 0.1 probability removal was used to develop the model. OR was estimated with $95 \%$ $\mathrm{CI}$ to show the strength of association and P-value $<.05$ was used to Declare statistical significance. The goodness of fit of the final model was checked using the HosmerLemeshow test of goodness at P-value $\geq .05$ (.135), model classification of accuracy was checked with $82.6 \%$ correctly classified and multicollinearity was assessed using standard errors of the Beta coefficients at $>2$.

\section{Ethical consideration}

The study has received ethical approval from Mekelle University, College of Health Science Ethical Review Board before commencement. Permission letter was obtained from Afar regional health bureau and Berahle woreda health office. 
Table 1 Cross tabulation of socio demographic characteristics of study participants with underweight status among 6-59 months old children in Berahle woreda, $2016(n=368)$

\begin{tabular}{|c|c|c|c|c|}
\hline \multirow[t]{2}{*}{ Variable } & \multirow[t]{2}{*}{ Category } & \multicolumn{3}{|c|}{ Underweight status of the children } \\
\hline & & Yes & No & Total \\
\hline \multirow[t]{5}{*}{ Age of the children } & $6-11$ months & $20(16.13)$ & $80(32.79)$ & $100(27.2)$ \\
\hline & $12-23$ months & $34(27.42)$ & $64(26.23)$ & $98(26.6)$ \\
\hline & 24-35 months & $20(16.13)$ & $46(18.85)$ & $66(17.9)$ \\
\hline & 36-47 months & $18(14.52)$ & $38(15.57)$ & $56(15.2)$ \\
\hline & 48-59 months & $32(25.80)$ & $16(6.56)$ & $48(13)$ \\
\hline \multirow[t]{2}{*}{ Residence } & Rural & $79(63.7)$ & $156(63.9)$ & $235(63.9)$ \\
\hline & Urban & $45(36.3)$ & $88(36.1)$ & $133(36.1)$ \\
\hline \multirow[t]{3}{*}{ Marital status } & Married & $100(80.6)$ & $200(82)$ & $280(76.1)$ \\
\hline & Formerly married & $20(16.2)$ & $34(13.9)$ & $54(20.1)$ \\
\hline & Single & $4(3.2)$ & $10(4.1)$ & $14(3.8)$ \\
\hline \multirow[t]{2}{*}{ Religion } & Muslim & $120(96.8)$ & $210(86.1)$ & $330(89.7)$ \\
\hline & Orthodox & $4(3.2)$ & $34(13.9)$ & $38(10.3)$ \\
\hline \multirow[t]{5}{*}{ Husbands occupation } & Farmer & $52(41.9)$ & $65(26.6)$ & $117(31.8)$ \\
\hline & Daily laborer & $4(3.2)$ & $12(4.9)$ & $16(4.3)$ \\
\hline & Employed & $28(22.6)$ & $87(35.7)$ & $115(31.2)$ \\
\hline & Merchant & $32(25.8)$ & $70(28.7)$ & $102(27.7)$ \\
\hline & Other & $8(6.5)$ & $10(41.1)$ & $18(4.9)$ \\
\hline \multirow[t]{2}{*}{ Educational status of mother } & Illiterate & $85(68.5)$ & $134(54.9)$ & $219(59.5)$ \\
\hline & Literate & $39(31.5)$ & $110(45.1)$ & $149(40.5)$ \\
\hline \multirow[t]{2}{*}{ Educational status of father } & Illiterate & $44(35.5)$ & $90(36.90$ & $134(36.4)$ \\
\hline & Literate & $80(64.5)$ & $154(63.1)$ & $234(63.6)$ \\
\hline \multirow[t]{3}{*}{ Income } & $<750$ & $24(19.4)$ & $37(15.2)$ & $61(16.5)$ \\
\hline & $750-1500$ & $68(54.8)$ & $121(49.6)$ & $189(51.3)$ \\
\hline & $>1500$ & $32(25.8)$ & $86(35.2)$ & $118(32.2)$ \\
\hline \multirow[t]{2}{*}{ Livestock ownership } & Yes & $72(58.1)$ & $134(54.9)$ & $206(56)$ \\
\hline & No & $52(41.9)$ & $110(45.1)$ & $162(44)$ \\
\hline \multirow[t]{3}{*}{ Decision maker } & Husband & $33(26.6)$ & $66(27)$ & $99(26.9)$ \\
\hline & Wife & $14(11.3)$ & $36(14.8)$ & $50(13.6)$ \\
\hline & Jointly & $77(62.1)$ & $142(58.2)$ & $219(59.5)$ \\
\hline \multirow[t]{2}{*}{ Family size } & $\leq 4$ & $30(24.2)$ & $72(29.5)$ & $102(27.7)$ \\
\hline & $>4$ & $94(75.8)$ & $172(70.5)$ & $266(72.3)$ \\
\hline \multirow[t]{2}{*}{ Number of $<5$ children in the house } & One & $66(53.2)$ & $120(49.2)$ & $186(50.5)$ \\
\hline & Greater one & $58(46.8)$ & $124(50.8)$ & $182(49.5)$ \\
\hline \multirow[t]{2}{*}{ Sex } & Male & $68(54.8)$ & $132(54.1)$ & $200(54.3)$ \\
\hline & Female & $56(45.2)$ & $112(45.9)$ & $168(45.7)$ \\
\hline \multirow[t]{2}{*}{ Birth weight $(\mathrm{N}=28)$} & $\geq 2500 \mathrm{~g}$ & $4(50)$ & $18(90)$ & $22(78.6)$ \\
\hline & $<2500 \mathrm{~g}$ & $4(50)$ & $2(10)$ & $8(23.4)$ \\
\hline \multirow[t]{3}{*}{ Size of the child during birth $(n=340)$} & Normal & $36(30.5)$ & $160(72.1)$ & $196(57.6)$ \\
\hline & Small & $80(67.8)$ & $42(18.9)$ & $122(35.9)$ \\
\hline & Big & $2(1.7)$ & $20(9)$ & $22(6.5)$ \\
\hline \multirow[t]{3}{*}{ Birth order } & 1 & $18(14.5)$ & $34(13.5)$ & $52(14.1)$ \\
\hline & $2-4$ & $34(27.4)$ & $118(48.4)$ & $152(41.3)$ \\
\hline & $>4$ & $72(58.1)$ & $92(37.7)$ & $164(44.6)$ \\
\hline \multirow[t]{2}{*}{ Diarrhea } & No & 78 (62.9) & $214(87.7)$ & $292(79.3)$ \\
\hline & Yes & $46(37.1)$ & $30(12.3)$ & 76 (20.7) \\
\hline \multirow[t]{2}{*}{ Cough } & No & $111(89.5)$ & $218(89.3)$ & $329(89.4)$ \\
\hline & Yes & $13(10.5)$ & $26(10.7)$ & 39 (10.6) \\
\hline
\end{tabular}


Table 1 (continued)

\begin{tabular}{|c|c|c|c|c|}
\hline \multirow[t]{2}{*}{ Variable } & \multirow[t]{2}{*}{ Category } & \multicolumn{3}{|c|}{ Underweight status of the children } \\
\hline & & Yes & No & Total \\
\hline \multirow[t]{2}{*}{ Fever } & No & $98(79)$ & $202(82.8)$ & $300(81.5)$ \\
\hline & Yes & $26(21)$ & $42(17.2)$ & $68(18.5)$ \\
\hline \multirow[t]{2}{*}{ Ever breast fed } & Yes & $124(100)$ & $244(100)$ & $368(100)$ \\
\hline & No & $0(0)$ & $0(0)$ & $0(0)$ \\
\hline \multirow[t]{2}{*}{ EBF } & No & $64(51.6)$ & $86(35.2)$ & $150(40.8)$ \\
\hline & Yes & $60(48.4)$ & $158(64.8)$ & $218(59.2)$ \\
\hline \multirow[t]{2}{*}{ Duration of EBF $(n=198)$} & $\geq 6$ months & $14(35)$ & $79(48.1)$ & $90(45.5)$ \\
\hline & $<6$ months & $26(65)$ & $82(51.9)$ & $108(54.5)$ \\
\hline \multirow[t]{2}{*}{ Beginning of CF } & $\geq 6$ months & $61(49.2)$ & $128(52.5)$ & $189(51.4)$ \\
\hline & $<6$ months & $63(51.8)$ & $116(47.5)$ & $179(48.6)$ \\
\hline \multirow[t]{3}{*}{ Cessation of $B F(n=224)$} & $>24$ months & $54(61.4)$ & $98(72.1)$ & $152(67.9)$ \\
\hline & $<24$ months & $26(29.5)$ & $36(26.5)$ & $62(27.7)$ \\
\hline & 24 months & $8(9.1)$ & $2(1.5)$ & $10(4.5)$ \\
\hline
\end{tabular}

\section{Results}

A total of 368 ( 124 cases and 244 controls) with a $98.1 \%$ response rate participated in this study. Of cases, 34 (27.4\%) were in the age group of $12-23$ months while 80 (32.8\%) controls were 6-11 months age group. All (100\%) children were ever breastfed and 64 (51.6\%) of the children were not exclusively breastfed but 158 (64.8\%) controls were exclusively breastfed (see Table 1).

Of participants, 154 (63.1\%) controls were meet the minimum dietary diversity score but 84 (67.7\%) cases were not meet the minimum dietary diversity score (see Table 2).

In multivariable logistic regression, variables with $\mathrm{P}$-value $<.25$ in binary logistic regression like age of the mother and child, educational level of mother, father's occupation, mother's occupation, monthly income, exclusive breastfeeding status, dietary diversity score, body mass index of mothers, birth interval, diarrhea, source of dirking water, faeces disposal system and latrine ownership were included into the model. Finally, the age of the child, Educational status of the mother, birth interval, diarrhea, dietary diversity score and source of drinking water were statistically significant predictors of underweight.

Being in the age group 48-59 months was 11.93 times $(\mathrm{AOR}=11.93$; 95\% CI 3.88-36.67) having underweight than children in the age group of 6-11 months. Illiterate mothers were 2.3 times $(\mathrm{AOR}=2.32$; 95\% CI $1.19-4.55$ ) at high risk of underweight compared to literate mothers. Children who got low dietary diversity score were 4.5 (AOR $=4.57$; 95\% CI 2.404-8.69) times more likely to become underweight than children who got the minimum acceptable dietary diversity. Children who had diarrhea in the past 2 weeks before data collection were 2933 times
$(\mathrm{AOR}=2.933 ; 95 \% \mathrm{CI} 1.469-5.854)$ higher odds of underweight than children without the diarrheal disease. Short interval ( $<3$ years) from the mother's previous childbirth was nearly five times more likely to have an underweight child than their counterpart with $(\mathrm{AOR}=5.17 ; 95 \% \mathrm{CI}$ 2.37-11.26). Children's families who used drinking unprotected water sources were 2.6 times more likely to have underweight children compared to those children whose families used drinking protected water sources with $(\mathrm{AOR}=2.626$; 95\% CI 1.42-4.85) (see Table 3).

\section{Discussion}

The result of this study revealed that the age of the child, educational status of the mother, birth interval, diarrhea, dietary diversity and source of drinking water were statistically associated determinant factors of children underweight.

The age group of 48-59 months was 11.93 times high odds of underweight than children in the age group of 6-11 months. This study is consistent with a study from Lalibela where children aged from 48 to 59 months were about 2.9 times more likely to be underweight than children 6-11 months old. The difference in the strength of association may be due to study design. Studies done from Ghana, Egypt and Tigray [21, 26, 27] revealed that children in 12-23 and 23-35 months were highly affected by underweight. This might be explained by the fact that 48 to 59 months old children are more active and lose a greater amount of energy that makes them underweight. Besides, mothers or caregivers may give more care for the new births.

Illiterate mothers were at higher risk of having underweight children. Studies conducted in Somali, Brazil, 
Table 2 Cross tabulation of child caring practice, maternal, environmental, and dietary diversity characteristics with underweight status among 6-59 months old children in Berahle woreda, Afar, Northern East Ethiopia, 2016

\begin{tabular}{|c|c|c|c|c|}
\hline \multirow[t]{2}{*}{ Variable } & \multirow[t]{2}{*}{ Category } & \multicolumn{3}{|c|}{ Underweight status of the children } \\
\hline & & Yes & No & Total \\
\hline \multirow[t]{2}{*}{ Minimum dietary diversity } & Meet & $40(32.3)$ & $154(63.1)$ & $194(52.7)$ \\
\hline & Not meet & $84(67.7)$ & $90(36.9)$ & $174(47.3)$ \\
\hline \multirow[t]{2}{*}{$\operatorname{MMF}(n=198)$} & Not accepted & $29(53.7)$ & $82(56.9)$ & $111(56.1)$ \\
\hline & Accepted & $25(46.3)$ & $62(43.1)$ & $87(43.9)$ \\
\hline \multirow[t]{2}{*}{ BCG vaccination } & Yes & $31(25)$ & $72(29.5)$ & $103(27)$ \\
\hline & No & $93(75)$ & $172(70.5)$ & $265(73)$ \\
\hline \multirow{2}{*}{ Measles vaccination status $(n=310)$} & Vaccinated & $77(67.5)$ & $123(62.8)$ & $200(64.5)$ \\
\hline & Not vaccinated & $37(32.5)$ & $73(37.2)$ & $110(35.5)$ \\
\hline \multirow[t]{4}{*}{ Mothers age } & $15-24$ & $25(20.2)$ & $66(27)$ & $91(24.7)$ \\
\hline & $25-34$ & $52(41.9)$ & $114(46.7)$ & $166(45.1)$ \\
\hline & $35-44$ & $37(29.8)$ & $60(24.6)$ & $97(26.4)$ \\
\hline & $>44$ & $10(8.1)$ & $4(1.6)$ & $14(3.8)$ \\
\hline \multirow[t]{3}{*}{ BMI } & Underweight & $60(48.4)$ & $36(14.8)$ & $96(26.1)$ \\
\hline & Healthy weight & $60(48.4)$ & $204(83.6)$ & $264(71.7)$ \\
\hline & Overweight & $4(3.20$ & $4(1.6)$ & $8(2.2)$ \\
\hline \multirow[t]{3}{*}{ Parity } & 1 & $18(14.5)$ & $42(17.2)$ & $60(16.3)$ \\
\hline & $2-3$ & $33(26.6)$ & $105(43)$ & $1381(37.5)$ \\
\hline & $>3$ & $73(58.9)$ & $97(39.8)$ & $170(46.2)$ \\
\hline \multirow[t]{2}{*}{ Birth interval $(n=322)$} & $\geq 3$ & $16(15.1)$ & $92(42.6)$ & $108(33.5)$ \\
\hline & $<3$ & $90(84.9)$ & $124(57.4)$ & $214(66.5)$ \\
\hline \multirow[t]{2}{*}{ Source of water } & Protected & $60(48.4)$ & $180(73.8)$ & $240(65.2)$ \\
\hline & Not protected & $64(51.6)$ & $64(26.2)$ & $128(34.8)$ \\
\hline \multirow[t]{2}{*}{ Latrine availability } & No & $82(66.1)$ & $94(38.5)$ & $176(47.8)$ \\
\hline & Yes & $42(33.9)$ & $150(61.5)$ & $192(52.2)$ \\
\hline \multirow[t]{2}{*}{ Hand washing before food preparation. } & No & $6(4.8)$ & $12(4.9)$ & $18(4.8)$ \\
\hline & Yes & $118(95.2)$ & $232(95.1)$ & $358(95.2)$ \\
\hline \multirow[t]{2}{*}{ Hand washing before \&after feeding } & No & $10(8.1)$ & $16(6.6)$ & $26(7)$ \\
\hline & Yes & $114(91.9)$ & $228(93.4)$ & $342(93)$ \\
\hline \multirow[t]{2}{*}{ Hand washing after toilet } & No & $41(33.1)$ & $72(29.5)$ & $113(30.7)$ \\
\hline & Yes & $83(66.9)$ & $172(70.5)$ & $255(69.3)$ \\
\hline \multirow[t]{2}{*}{ Hand washing after child cleaning } & No & $62(50)$ & $121(49.6)$ & $183(49.7)$ \\
\hline & Yes & $62(50)$ & $123(50.4)$ & $185(51.3)$ \\
\hline \multirow[t]{2}{*}{ Cereal } & Yes & $124(100)$ & $230(94.2)$ & $354(96.1)$ \\
\hline & No & 0 & $14(5.8)$ & $14(3.9)$ \\
\hline \multirow[t]{2}{*}{ Legume and nut } & Yes & $86(65.6)$ & $136(57.4)$ & $222(60.3)$ \\
\hline & No & $45(34.4)$ & $101(42.6)$ & $146(39.7)$ \\
\hline \multirow[t]{2}{*}{ Dairy product } & Yes & $84(64)$ & $178(75)$ & $262(71.1)$ \\
\hline & No & $47(36)$ & $59(25)$ & $106(28.9)$ \\
\hline \multirow[t]{2}{*}{ Flesh food } & Yes & $28(21.3)$ & $84(35.4)$ & $112(30.5)$ \\
\hline & No & $103(78.7)$ & $153(64.6)$ & $256(69.5)$ \\
\hline \multirow[t]{2}{*}{ Egg } & Yes & $6(4.6)$ & $36(15.2)$ & $42(11.5)$ \\
\hline & No & $125(95.4)$ & $201(84.8)$ & $326(88.5)$ \\
\hline \multirow[t]{2}{*}{ Vitamin A rich fruit and veg } & Yes & $14(10.7)$ & $48(20.3)$ & $62(16.9)$ \\
\hline & No & $117(89.3)$ & $189(79.7)$ & $306(83.1)$ \\
\hline
\end{tabular}


Table $3 \mathrm{Bi}$ variate and multivariable analysis participants on determinants of underweight among 6-59 months old children in Berahle, Afar, Northern East Ethiopia, $2016(n=368)$

\begin{tabular}{|c|c|c|c|c|c|}
\hline Categories & Case (124) & Control (244) & COR $(95 \% \mathrm{Cl})$ & AOR $(95 \% \mathrm{Cl})$ & P-value \\
\hline \multicolumn{6}{|l|}{ Mothers occupation } \\
\hline House wife & $74(59.7)$ & $124(50.8)$ & 1 & & \\
\hline Others & $50(40.3)$ & $120(49.2)$ & $.69(.45-1.08)$ & & \\
\hline \multicolumn{6}{|l|}{ Fathers occupation } \\
\hline Farmer & $70(56.5)$ & 99 (40.6) & 1 & & \\
\hline Employed & $20(16.1)$ & $72(29.5)$ & $.39(.22-.70)$ & & \\
\hline Merchant & $22(17.7)$ & $51(20.9)$ & $.61(.33-1.09)$ & & \\
\hline Other & $12(9.7)$ & $22(9)$ & $.77(.35-1.66)$ & & \\
\hline \multicolumn{6}{|l|}{ Mothers literacy } \\
\hline Illiterate & $85(68.5)$ & $134(54.9)$ & $1.78(1.13-2.82)$ & $2.32(1.19-4.55)^{*}$ & .014 \\
\hline Literate & $39(31.5)$ & $110(45.1)$ & 1 & & \\
\hline \multicolumn{6}{|l|}{ Income } \\
\hline$<750$ & $24(19.4)$ & $37(15.2)$ & $1.74(.90-3.35)$ & & \\
\hline $750-1500$ & $68(54.8)$ & $121(49.6)$ & $1.51(.913-2.49)$ & & \\
\hline$>1500$ & $32(25.8)$ & $86(35.2)$ & 1 & & \\
\hline \multicolumn{6}{|l|}{ Age of children } \\
\hline 6-11 months & $20(16.1)$ & $80(32.8)$ & 1 & & \\
\hline $12-23$ months & $34(27.4)$ & $64(26.2)$ & $2.12(1.11-4.04)$ & $1.03(.41-2.53)$ & .948 \\
\hline 24-35 months & $20(16.1)$ & $46(18.9)$ & $1.74(.84-3.56)$ & $1.71(.66-4.41)$ & .265 \\
\hline 36-47 months & $18(14.5)$ & $38(15.6)$ & $1.90(.90-3.99)$ & $1.77(.69-4.56)$ & .231 \\
\hline 48-49 months & $32(25.8)$ & $16(6.8)$ & $8(3.68-17.36)$ & $11.93(3.88-36.67)^{*}$ & .000 \\
\hline \multicolumn{6}{|l|}{ Birth order } \\
\hline 1 & $18(14.5)$ & $42(17.2)$ & 1 & & \\
\hline $2-3$ & $33(26.6)$ & $105(43)$ & $.73(.37-1.44)$ & & \\
\hline$>3$ & $73(58.9)$ & 97 (39.8) & $1.70(.93-3.29)$ & & \\
\hline \multicolumn{6}{|l|}{ Diarrhea } \\
\hline No & $78(62.9)$ & $214(87.7)$ & 1 & & \\
\hline Yes & $46(37.1)$ & $30(12.3)$ & $4.2(2.48-7.13)$ & $2.93(1.46-5.85)^{*}$ & .002 \\
\hline \multicolumn{6}{|l|}{ EBF status } \\
\hline No & 64 (51.6) & $86(35.2)$ & $1.96(1.26-3.04)$ & & \\
\hline Yes & $60(48.4)$ & $158(64.8)$ & 1 & & \\
\hline \multicolumn{6}{|l|}{ EBF duration } \\
\hline$\geq 6$ months & $14(35)$ & $79(48.1)$ & 1 & & \\
\hline$<6$ months & $26(65)$ & $82(51.9)$ & $1.72(.83-3.53)$ & & \\
\hline \multicolumn{6}{|l|}{ Score diet diversity } \\
\hline Meet & $40(32.3)$ & $154(63.1)$ & 1 & & \\
\hline Not meet & $84(67.7)$ & $90(36.9)$ & $3.59(2.27-5.67)$ & $4.57(2.40-8.69)^{*}$ & .001 \\
\hline \multicolumn{6}{|l|}{ Source of water } \\
\hline Protected & $60(48.4)$ & $180(73.8)$ & 1 & & \\
\hline Not protected & $64(51.6)$ & $64(26.2)$ & $3(1.90-4.7)$ & $2.62(1.42-4.85)^{*}$ & .002 \\
\hline \multicolumn{6}{|l|}{ Latrine ownership } \\
\hline No & $82(66.1)$ & $94(38.5)$ & $3.11(1.98-4.89)$ & & \\
\hline Yes & $42(33.9)$ & $150(61.5)$ & 1 & & \\
\hline \multicolumn{6}{|l|}{ Faeces disposal system } \\
\hline Proper disposal & $56(45.2)$ & $131(53.7)$ & 1 & & \\
\hline Improper disposal & $68(54.8)$ & $113(46.3)$ & $.71(.46-1.09)$ & & \\
\hline \multicolumn{6}{|l|}{ Body mass index } \\
\hline Underweight & $63(50.8)$ & $83(34)$ & $2(1.29-3.11)$ & & \\
\hline Normal weight & $61(49.2)$ & $161(66)$ & 1 & & \\
\hline
\end{tabular}


Table 3 (continued)

\begin{tabular}{llllll}
\hline Categories & Case (124) & Control (244) & COR (95\% Cl) & AOR (95\% Cl) & P-value \\
\hline Birth interval & $16(15.1)$ & $92(42.6)$ & 1 & & \\
$\geq 3$ & $90(84.9)$ & $124(57.4)$ & $4.17(2.29-7.57)$ & $5.17(2.37-11.26)^{*}$ \\
$<3$
\end{tabular}

AOR adjusted odds ratio, $\mathrm{Cl}$ confidence interval

* Significant predictors at P-value $<.05$. Variables with P-value $<.25$ in the bivariable analysis (COR) were included to the final model for adjustment (AOR)

Arba Minch, Gondar, Nepal, Nigeria, and Tanzania have a consistent result with this study [28-34]. Being illiterate mothers were 3.28 times and 1.4 times at high risk for underweight in Brazil [29] and Arba Minch [30] respectively. This slight difference in the strength of association may be due to study design, sample size and geographical location. It seems plausible that the educational status of the mother affects awareness of exclusive breastfeeding and complementary feeding practice and thus could affect their weight status.

Diarrhea was also a significant determinant of underweight. Children with diarrhea in the past 2 weeks were 2.933 times more likely to be underweight than those who had no diarrhea. Even though there is a slight difference in the strength of association among many studies, the finding of this study was consistent with the following cited researches [21,35-38]. This might be due to less health care support, poor hygiene, and sanitation.

The source of drinking water is also a major determinant of underweight in this study. This is supported by studies done in Ethiopia [23]. Nigeria [39] and Brazil [29]. The possible explanation might be due to access to clean water reduces the chance of exposure of the child to water-borne diseases like diarrhea.

Another determinant variable for this study was a dietary diversity score where children who were not meet minimum dietary diversity score were 4.57 times more likely to become underweight. Similar studies were also seen in Nekemt [40], Arba Minch [30] and Teheran [41]. This might be due to diversified food reflects higher dietary quality and a greater possibility of meeting the daily energy and nutrient requirements of children.

Short interval from mother's previous birth was a risk factor for underweight. The result of this study is supported by studies done in Teheran [41, 42]. This might be from its effect through decreasing birth weight and children born within 3 years of a sibling are generally prone to inadequate care from their mothers.

\section{Conclusion}

This study identifies multiple risk factors for child underweight status. Being in Age group of 48-59 months, being illiterate, less than 3 years of birth interval, diarrhea, not meet minimum dietary diversity score and using an unprotected source of drinking water were statistically significant determinants of underweight. The varieties of risk factors identified in this study emphasize the need for a multidisciplinary approach to address the issues of child underweight. Women development army, community health workers, Woreda health office, and NGOs like Goal Ethiopia and Woreda water supply office should emphasize the determinant factors.

\section{Limitations}

There may also some limitations in the study like; Recall bias and inaccurate responses like age and the nutritional factors.

\section{Abbreviations \\ AOR: adjusted odd ratio; BMI: body mass index; Cl: confidence interval; COR: crude odd ratio; DALY: disability-adjusted life year; MEDHS: Mini Ethiopian Demographic Health Survey; IQR: inter quartile range; OR: odd ratio; SDG's: sustainable developmental goals; SPSS: statistical packaging for social science; SSA: Sub Saharan Africa; UNICEF: United Nations Children's Fund; WHO: World Health Organization.}

\section{Acknowledgements}

Our special gratitude also goes to Afar regional health bureau and Berahle woreda health office and study participants for giving me valuable information.

\section{Authors' contributions}

SH originally develop the proposal. SH and KG conduct the study. SH and KG develop the first draft of the manuscript. SH and KG contributed to data analysis, a revised draft of the paper. Both authors read and approved the final manuscript.

\section{Funding}

The study was financially supported by Mekelle University. Mekelle University support for design of the study, data collection, data analysis and interpretation. However, the budget for Writing of Manuscript is not covered by the university. We prepared write the manuscript ourselves without any budget.

\section{Availability of data and materials}

The data sets used and analyzed during the current study available from the corresponding author on reasonable request.

\section{Ethics approval and consent to participate}

The study has obtained ethical approval from Mekelle University Institutional Review Board before its commencement. The aim of the study was explained and informed written consent was obtained from each study participant. Permission letter was also obtained from Afar Regional Health Bureau and Berahle wereda Health Office. 


\section{Consent to publish \\ Not applicable.}

\section{Competing interests}

The authors declare that they have no competing interests.

\section{Author details}

${ }^{1}$ Department of Epidemiology and Biostatistics, School of Public Health, College of Health Science, Aksum University, P. O. Box: 298, Aksum, Ethiopia. ${ }^{2}$ Department of Nutrition, School of Public Health, College of Health Science, Aksum University, Aksum, Ethiopia.

Received: 4 September 2019 Accepted: 12 November 2019

Published online: 19 November 2019

\section{References}

1. Park JE, Park K. Park's textbook of preventive of social medicine. 29th ed. Jabalpur: Banarsidas Bhanol; 2007

2. World Health Organization. Management of severe malnutrition: a manual for physicians and other senior health workers. Geneva: WHO; 1999. p. 1-68.

3. Serrano E. What should I do if my child is underweight? Virginia cooperative extension programs. 2009. p. 348-271.

4. United Nations Children's Fund. Improving child nutrition the achievable imperative for global progress. New York: UNICEF; 2013. p. 1-16, 56-67.

5. Save The Children. A life free from hunger tackling child malnutrition. Geneva: Save The Children; 2012. p. 1-96.

6. Wagstaff A, Watanabe N. Socioeconomic inequalities in child malnutrition in the developing world. 2000. p. 1-93.

7. Haddad L. The right ingredients: the need to invest in child nutrition. London: UNICEF; 2011.

8. World Bank. Health, nutrition and population sector strategy. Washington, DC: The World Bank; 1997.

9. Amsalu S, Tigabu Z. Risk factors for severe acute malnutrition in children under the age of five. Ethiop J Health Dev. 2007.

10. EMOH. National Nutrition Program June 2013-June 2015: Government of the Federal Democratic Republic of Ethiopia. 2012.

11. UNICEF. United Nations Children's Fund (UNICEF). New York: The World Bank; 2009.

12. Victora CG, Adair L, Fall C, Hallal PC, Martorell R, Richter L, et al. Maternal and child undernutrition: consequences for adult health and human capital. Lancet. 2008;371:340-57.

13. Global Health Observatory visualization. Joint child malnutrition estimates (UNICEF-WHO-WB), Regional prevalence and numbers of stunting, underweight and overweight (1990-2014).

14. United Nations Children Fund, World Health Organization, World Bank. Estimates for 2012 and launch of interactive data dashboards. UNICEF, WHO, WB; 2013. p. 1-45.

15. United Nation Children Fund, World Health Organization, World Bank. Levels \& trends in child malnutrition: UNICEF, WHO-the World Bank joint child malnutrition estimates. 2016. p. 1-12

16. United Nations Children Fund United Kingdom. The right ingredients: the need to invest in child nutrition UNICEF United Kingdom. 2011. p. 1-23.

17. Central Statistical Agency. Ethiopia Mini Demographic and Health Survey 2014. Addis Ababa: Central Statistical Agency; 2014. p. 1-110.

18. Amsalu S, Tigabu Z. Risk factors for severe acute malnutrition in children under the age of five. Ethiop J Health Dev. 2008;22(1).

19. Yalew BM. Prevalence of malnutrition and associated factors among children age 6-59 months at Lalibela Town Administration, North Wollo Zone, Anrs, Northern Ethiopia. Nutr Disord Ther. 2014;4(1):132.

20. Kavosi E, Rostami ZH, Kavosi Z, Nasihatkon A, Moghadami M, Heidari M. Prevalence and determinants of under-nutrition among children under six: a cross-sectional survey in Fars province, Iran. Int J Health Policy Manag. 2014;3(2):71-6.

21. Miah R. Risk factors for undernutrition in children under five years in Ghana. 2014.

22. Mahgoub SEO, Nnyepi M, Bandeke T. Factors affecting prevalence of malnutrition among children under three years of age in Botswana. Afr J Food Agric Nutr Dev. 2006;6(1):5-6.
23. Bantamen G, Belaynew W, Dube J. Assessment of factors associated with malnutrition among under five years age children at Machakel Woreda, Northwest Ethiopia: a case-control study. Nutr Food Sci. 2014;4(1):256.

24. Rodriguez-Llanes JM, Ranjan-Dash S, Degomme O, Mukhopadhyay A. Child malnutrition and recurrent flooding in rural eastern India: a community-based survey. BMJ Open. 2011;1:e000109.

25. Tamiru MW, Tolessa BE, Abera SF. Under nutrition and associated factors among under-five age children of Kunama Ethnic Groups in Tahtay Adiyabo Woreda, Tigray, Ethiopia: community study. Int J Nutr Food Sci. 2015;4(3):278-89.

26. El-Sayed N, Mohamed AG, Nofal L, Mahfouz A, Zeid HA. Malnutrition among pre-school children in Alexandria, Egypt. J Health Popul Nutr. 2001;19(4):275-80.

27. Alemayehu M, Tinsae F, Haileslassie K, Seid O, Gebregziabher G, Yebyo $H$. Nutritional status and associated factors among under-five children, Tigray, Northern Ethiopia. Int J Nutr Food Sci. 2014;3(6):579-86.

28. Demissie S, Worku A. Magnitude and factors associated with malnutrition in children 6-59 months of age in the pastoral community of Dollo Ado district, Somali region, Ethiopia. Sci J Public Health. 2013:1(4):175-83

29. Horta BL, Santos RV, Welch JR, Cardoso AM, Santos JV, Assis AMO, et al. Nutritional status of indigenous children: findings from the First National Survey of Indigenous People's Health and Nutrition in Brazil. Int J Equity Health. 2013;12:23.

30. Tamiru D, Jisha H. Dietary patterns and anthropometric status of under-five children in Arba Minch Zuria, Gamo Gofa Zone: communitybased cross-sectional study. Adv Dairy Res. 2015;3(2):136.

31. Gultie T, Sisay E, Sebsibie G. Nutritional status and associated factors among orphan children below the age of five years in Gondar City. Ethiopia. J Food Nutr Sci. 2014;2(4):179-84.

32. Ruwali D. Nutritional status of children under five years of age and factors associated in Padampur VDC. Chitwan. Health Prospect. 2011:10:1-17.

33. Duru CB, Oluoha UR, Uwakwe KA, Diwe KC, Merenu IA. Prevalence and socio-demographic determinants of malnutrition among under-five children in rural communities in Imo State, Nigeria. Am J Public Health Res. 2015;3(6):199-206.

34. Abubakar A, Uriyo J, Msuya SE, Swai M, Stray-Pedersen B. Prevalence and risk factors for poor nutritional status among children in the Kilimanjaro region of Tanzania. Int J Environ Res Public Health. 2012;9:3506-18.

35. Asfaw M, Wondaferash M, Taha M, Dube L. Prevalence of undernutrition and associated factors among children aged between six to fiftynine months in Bule Hora district, South Ethiopia. BMC Public Health. 2015;15:41.

36. Maleta K. Growth and undernutrition in rural Malawi children. Tampere: University of Tampere; 2003. p. 1-49.

37. Fekadu Y, Mesfin A, Haile D, Stoecker BJ. Factors associated with the nutritional status of infants and young children in the Somali Region, Ethiopia: a cross-sectional study. BMC Public Health. 2015;15(846):1-9.

38. Yisak H, Gobena T, Mesfin F. Prevalence and risk factors for undernutrition among children under five at Haramaya district, Eastern Ethiopia. BMC Pediatr. 2015;15(212):1-7.

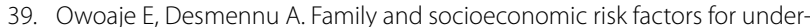
nutrition among children aged 6 to 23 months in Ibadan, Nigeria. Pan Afr Med J. 2014;17:161.

40. Hailemariam TW. Prevalence of underweight and its determinant factors of under two children in a rural area of Ethiopia. Food Sci Qual Manag. 2014:31:1-29.

41. Nojomi M, Tehran A, Najm-Abadi S. Risk analysis of growth failure in under-5-year children. Arch Iran Med. 2014;7(3):195-200.

42. Nojomi M, Tehrani A, Najm-Abadi S. Risk analysis of growth failure in under-5-year children. Arch Iran Med. 2004;7(3):195-200.

\section{Publisher's Note}

Springer Nature remains neutral with regard to jurisdictional claims in published maps and institutional affiliations. 